\title{
Evidence of tetraphenylporphyrin monoacids by ion-transfer voltammetry at polarized liquid|liquid interfaces $\dagger$
}

\author{
Bin Su, ${ }^{a}$ Fei Li, ${ }^{a}$ Raheleh Partovi-Nia, ${ }^{a}$ Claude Gros, ${ }^{b}$ Jean-Michel Barbe, ${ }^{b}$ \\ Zdenek Samec ${ }^{c}$ and Hubert H. Girault ${ }^{* a}$
}

Received (in Cambridge, UK) 11th July 2008, Accepted 4th August 2008

First published as an Advance Article on the web 12th September 2008

DOI: $10.1039 / b 811886 h$

\begin{abstract}
We present a simple methodology to illustrate the existence of tetraphenylporphyrin monoacid based on ion-transfer voltammetry at a polarized water|1,2-dichloroethane interface and organic $\mathrm{p} K$ values are also estimated.
\end{abstract}

The acid-base property of free-base porphyrins has been widely investigated, but the subject is still the matter of some controversy. ${ }^{1}$ The tetrapyrrole ring of a free-base porphyrin contains two tertiary nitrogen atoms, which allows the gain of protons to form a monoacid and a diacid, as illustrated for the free-base 5,10,15,20-meso-tetrapehenylporphyrin $\left(\mathrm{H}_{2} \mathrm{TPP}\right)$ in Scheme 1, and the existence of monoacids has received considerable attention. By titrating $\mathrm{H}_{2} \mathrm{TPP}$ usually one isosbestic point due to $\mathrm{H}_{2}$ TPP and $\mathrm{H}_{4} \mathrm{TPP}^{2+}$ is observed, whereas the intermediate $\mathrm{H}_{3} \mathrm{TPP}^{+}$could not be clearly detected. ${ }^{2}$

The existence of $\mathrm{H}_{3} \mathrm{TPP}^{+}$, as well as $\mathrm{p} K_{\mathrm{a} 1}$ and $\mathrm{p} K_{\mathrm{a} 2}$ values, has been reported in a few cases, ${ }^{3-6}$ one of which is based on the ion-transfer voltammetry at a polarized water|nitrobenzene interface. ${ }^{6}$ Since the pioneering work of Koryta et al., ${ }^{7}$ ion transfer voltammetry at the liquid|liquid interface (also called the Interface between Two Immiscible Electrolyte Solutions (ITIES)) has become a well-established method to study the acid-base properties of molecules dissolved in an organic phase in contact with an aqueous electrolyte. As shown by Reymond et al. for the study of therapeutic molecules, this methodology allows the determination of $\mathrm{p} K$ values, and the drawing of ionic partition diagrams. ${ }^{8}$ Herein, using this simple methodology, we illustrate the existence of $\mathrm{H}_{3} \mathrm{TPP}^{+}$in 1,2-dichloroethane (DCE) and $\mathrm{p} K_{\mathrm{a} 1}$ and $\mathrm{p} K_{\mathrm{a} 2}$ values are also estimated.

An ITIES is formed when an aqueous solution containing hydrophilic ions is put in contact with an organic solution containing lipophilic ions. Electrochemical polarization supplied by an external voltage can give a polarizable potential window, the width of which is defined by the transfer reactions

\footnotetext{
${ }^{a}$ Laboratoire d'Electrochimie Physique et Analytique, Ecole Polytechnique Fédérale de Lausanne, Station 6, CH-1015 Lausanne, Switzerland.E-mail: hubert.girault@epfl.ch;$$
\text { Fax: + } 4121 \text { 6933667; Tel: + } 41216933145
$$

${ }^{b}$ Institut de Chimie Moléculaire de l'Université de Bourgogne, ICMUB-UMR 5260, 21078 Dijon Cedex, France

${ }^{c}$ J. Heyrovsky Institute of Physical Chemistry of ASCR, v.v.i,

Dolejskova 3, 18223 Prague 8, Czech Republic

$\dagger$ Electronic supplementary information (ESI) available: Fig. S1: Cyclic voltammetry of $50 \mu \mathrm{M} \mathrm{H}_{2} \mathrm{TPP}$ at various scan rates. Fig. S2: Cyclic voltammetry at various concentrations of $\mathrm{H}_{2}$ TPP. Fig. S3: CVs at various aqueous $\mathrm{pH}$. See DOI: 10.1039/b811886h
}

of the electrolyte ions across the interface. The potential dependence for ion transfer across the interface follows a Nernst equation. For example, using $10 \mathrm{mM} \mathrm{LiCl}$ and $100 \mathrm{mM} \mathrm{HCl}$ as the aqueous electrolytes and bis(triphenylphosphoranylidene)ammonium tetrakis(pentafluorophenyl)borate (BTPPATPFB, $5 \mathrm{mM}$ ) as the lipophilic electrolyte in DCE, a potential window ranging from -0.5 to $0.4 \mathrm{~V}$ can be obtained, as shown by the dotted line in Fig. 1(a). This window is determined by the transfer of $\mathrm{H}^{+}$and $\mathrm{Cl}^{-}$from water to DCE at positive and negative potentials, respectively. With the help of an ionophore present in DCE that can complex with $\mathrm{H}^{+}$, the transfer of $\mathrm{H}^{+}$will be facilitated and a wave will appear in the middle of the potential window. Stated in another way, $\mathrm{H}^{+}$will transfer at less positive potentials in this case, due to the presence of a proton acceptor in the organic phase. This phenomenon is usually called facilitated ion transfer reaction (or Transfer by Interfacial Complexation, TIC) ${ }^{9}$ and the shift of the transfer potential provides information on the complexation constant between the ionophore and $\mathrm{H}^{+}$.

By dissolving $50 \mu \mathrm{M} \mathrm{H}_{2}$ TPP in a DCE solution containing a lipophilic salts (BTPPATPFB, $5 \mathrm{mM}$ ) in contact with an acidic aqueous solution $(10 \mathrm{mM} \mathrm{LiCl}$ and $100 \mathrm{mM} \mathrm{HCl})$, two waves can be observed in the cyclic voltammogram, as illustrated by the full line in Fig. 1(a). The two waves, featuring the same current magnitude, lie at $0.046 \mathrm{~V}\left(\Delta_{\mathrm{o}}^{\mathrm{w}} \phi_{1}\right)$ and $0.262 \mathrm{~V}\left(\Delta_{\mathrm{o}}^{\mathrm{w}} \phi_{2}\right)$, respectively. First of all, the peak-to-peak potential separations for the two waves are approximately $60 \mathrm{mV}$, which complies with the conditions for a reversible transfer of a singly charged ion. The maximum peak currents are in good agreement with the Randles-Sevcik equation as shown by the linear dependence on the square root of scan rate, indicating that both waves originate from diffusion-controlled reactions. The measured peak currents also linearly increase with the $\mathrm{H}_{2}$ TPP concentration in the range 50 to $200 \mu \mathrm{M}$. This confirms that the ion transfer reactions are limited by the diffusion of $\mathrm{H}_{2}$ TPP species in the organic phase. Indeed, the proton concentration in water is in excess compared with that

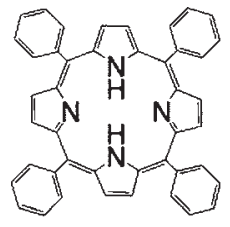

$\mathrm{H}_{2}$ TPP

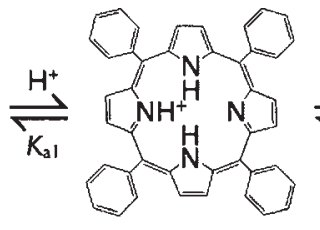

$\mathrm{H}_{3} \mathrm{TPP}^{+}$

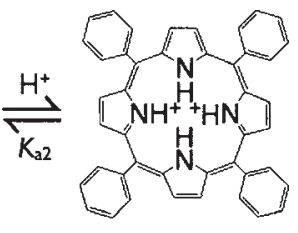

$\mathrm{H}_{4} \mathrm{TPP}^{2+}$
Scheme 1 Protonation of $\mathrm{H}_{2}$ TPP to form monoacid and diacid. 

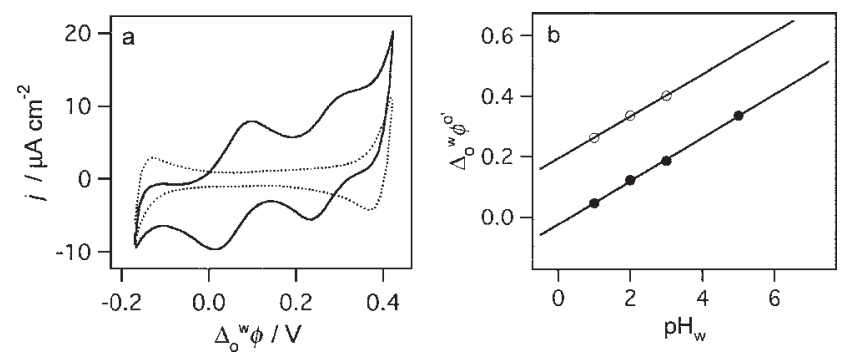

Fig. 1 (a) Cyclic voltammograms in the absence $(. .$.$) and presence$ (-) of $50 \mu \mathrm{M} \mathrm{H} \mathrm{H}_{2}$ TPP in DCE at a scan rate of $0.025 \mathrm{~V} \mathrm{~s}^{-1}$. Electrolytes: $10 \mathrm{mM} \mathrm{LiCl}$ and $100 \mathrm{mM} \mathrm{HCl}$ in water and $5 \mathrm{mM}$ BTPPATPFB in DCE. (b) $\mathrm{pH}$ dependence of the half-wave potentials of the two waves.

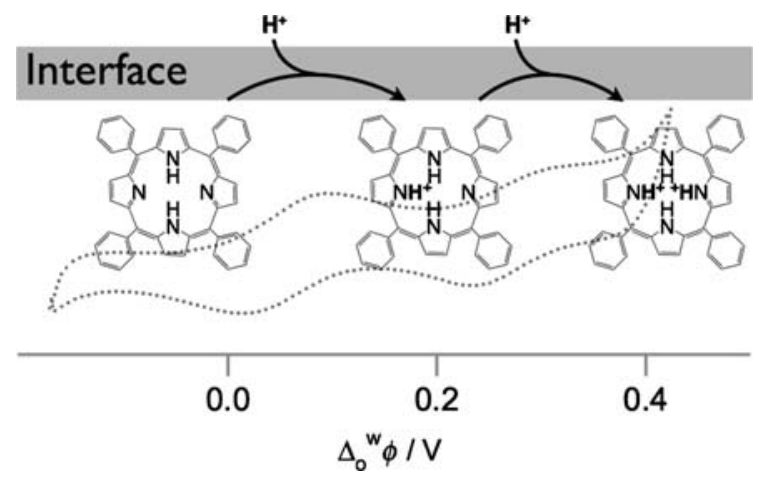

Scheme 2 Illustration of interfacial formation of $\mathrm{H}_{3} \mathrm{TPP}^{+}$and $\mathrm{H}_{4} \mathrm{TPP}^{2+}$.

of $\mathrm{H}_{2}$ TPP in DCE. Furthermore, the two waves shift with the acidity of aqueous phase by approximately $60 \mathrm{mV} \mathrm{pH}^{-1}$, as illustrated in Fig. 1(b), confirming that both waves correspond to a facilitated proton transfer reaction. As illustrated in Scheme 2, the first wave represents the transfer of a proton from water to DCE facilitated by $\mathrm{H}_{2}$ TPP that in fact is the first protonation of $\mathrm{H}_{2} \mathrm{TPP}$ to form the monoacid $\mathrm{H}_{3} \mathrm{TPP}^{+}$in DCE, and the second one represents the facilitated transfer of a second proton by $\mathrm{H}_{3} \mathrm{TPP}^{+}$. These two processes can be expressed as:

$$
\begin{aligned}
\mathrm{H}_{2} \mathrm{TPP}_{(\mathrm{DCE})}+\mathrm{H}^{+}{ }_{(\mathrm{W})} & \rightleftharpoons \mathrm{H}_{3} \mathrm{TPP}^{+}{ }_{(\mathrm{DCE})} \\
\mathrm{H}_{3} \mathrm{TPP}^{+}{ }_{(\mathrm{DCE})}+\mathrm{H}^{+}{ }_{(\mathrm{W})} & \rightleftharpoons \mathrm{H}_{4} \mathrm{TPP}^{2+}{ }_{(\mathrm{DCE})}
\end{aligned}
$$

As illustrated in Fig. 1(a), the facilitated transfer of $\mathrm{H}^{+}$in the presence of $\mathrm{H}_{2}$ TPP and $\mathrm{H}_{3} \mathrm{TPP}^{+}$is occurring at lower potentials than that of $\mathrm{H}^{+}$alone.

In addition, considering the two processes represent a $1: 1$ complexation reaction controlled by the diffusion of the porphyrin species in the organic phase, $K_{\mathrm{a} 1}$ and $K_{\mathrm{a} 2}$ can be estimated by exploring the $\mathrm{pH}$ dependence of the apparent transfer potential according to the following equation: ${ }^{10}$

$$
\begin{aligned}
\Delta_{\mathrm{o}}^{\mathrm{w}} \phi_{\mathrm{LH}^{+}}^{1 / 2}= & \Delta_{\mathrm{o}}^{\mathrm{w}} \phi_{\mathrm{H}^{+}}^{\mathrm{o}^{\prime}}+\frac{R T}{2 F} \ln \left(\frac{D_{\mathrm{L}}}{D_{\mathrm{LH}^{+}}}\right) \\
& -\frac{2.303 R T}{F} \mathrm{p} K_{\mathrm{a}}^{\mathrm{DCE}}+\frac{2.303 R T}{F} \mathrm{pH}^{\mathrm{w}}
\end{aligned}
$$

where $\Delta_{\mathrm{o}}^{\mathrm{w}} \phi_{\mathrm{LH}^{+}}^{1 / 2}$ is the half-wave transfer potential of the respective facilitated proton transfers. $\Delta_{\mathrm{O}}^{\mathrm{w}} \phi_{\mathrm{H}^{+}}^{\mathrm{o}^{\prime}}$ is the formal transfer potential for the transfer of $\mathrm{H}^{+} . D_{\mathrm{L}}$ and $D_{\mathrm{LH}^{+}}(\mathrm{L}=$ $\mathrm{H}_{2}$ TPP, $\mathrm{H}_{3} \mathrm{TPP}^{+}$) represent the diffusion coefficients of the proton acceptor ligand and its protonated form, and for simplicity it can be assumed that $D_{\mathrm{L}} \approx D_{\mathrm{LH}^{+}} ; \mathrm{pH}^{\mathrm{w}}$ is the aqueous $\mathrm{pH}$. The relationship between $\Delta_{\mathrm{o}}^{\mathrm{w}} \phi$ and the $\mathrm{pH}^{\mathrm{w}}$ is found to be linear, and the intercept allows the determination of the $\mathrm{p} K_{\mathrm{a}}$ in the organic phase. $K_{\mathrm{a}}^{\mathrm{DCE}}$ is defined by:

$$
K_{\mathrm{a}}^{\mathrm{DCE}}=\frac{a_{\mathrm{L}}^{\mathrm{DCE}} a_{\mathrm{H}^{+}}^{\mathrm{DCE}}}{a_{\mathrm{LH}^{+}}^{\mathrm{DCE}}}
$$

Doing so, as shown in Fig. $1(\mathrm{~b}), \mathrm{p} K_{\mathrm{a} 1}^{\mathrm{DCE}}$ and $\mathrm{p} K_{\mathrm{a} 2}^{\mathrm{DCE}}$ here are found to be equal to 9.8 and 6.0 , which show that both $\mathrm{H}_{3} \mathrm{TPP}^{+}$and $\mathrm{H}_{4} \mathrm{TPP}^{2+}$ are very weak acids in DCE. Meanwhile, it suggests that both $\mathrm{H}_{2}$ TPP and $\mathrm{H}_{3} \mathrm{TPP}^{+}$are weak bases, having a small affinity for protons. It is worthwhile to mention that the proton activity in DCE is very small and the lack of hydrogen bonds in DCE prevents the stabilization of the protonated species and favours the presence of neutral or low charges species.

In conclusion, we present a simple methodology to illustrate the existence of $\mathrm{H}_{3} \mathrm{TPP}^{+}$in DCE, based on ion-transfer voltammetry at the water|1,2-dichloroethane interface. $K_{\mathrm{a} 1}$ and $K_{\mathrm{a} 2}$ values can be accurately determined.

This work is financially supported by EPFL, European COST Action (D36/007/06) and the Grant Agency of the Czech Republic (no. 203/07/1257). The technical assistance of Valerie Devaud is also acknowledged.

\section{Notes and references}

1 P. Hambright, in The Porphyrin Handbook, ed. K. M. Kadish, K. M. Smith and R. Guilard, 2000, p. 129.

2 S. Aronoff and C. A. Weast, J. Org. Chem., 1941, 6, 550.

3 S. Aronoff, J. Phys. Chem., 1958, 62, 428.

4 G. De Luca, A. Romeo, L. M. Scolaro, G. Ricciardi and A. Rosa, Inorg. Chem., 2007, 46, 5979.

5 O. Almarsson, A. Blasko and T. C. Bruice, Tetrahedron, 1993, 49, 10239.

6 X. H. Xia, W. D. Su and S. M. Zhou, J. Electroanal. Chem., 1992, 324, 59.

7 J. Koryta, P. Vanysek and M. Brezina, J. Electroanal. Chem., 1976, 67, 263 .

8 F. Reymond, G. Steyaert, P.-A. Carrupt, B. Testa and H. Girault, J. Am. Chem. Soc., 1996, 118, 11951.

9 Y. Shao, M. D. Osborne and H. H. Girault, J. Electroanal. Chem., 1991, 318, 101.

10 H. Matsuda, Y. Yamada, K. Kanamori, Y. Kudo and Y. Takeda, Bull. Chem. Soc. Jpn., 1991, 64, 1497. 